\title{
Domain Specific Self-Efficacy Mediates the Impact of Pain Catastrophizing on Pain and Disability in Overweight and Obese Osteoarthritis Patients
}

\author{
Rebecca A. Shelby, $\mathrm{PhD}^{1}$, Tamara J. Somers, PhD ${ }^{1}$, Francis J Keefe, $\mathrm{PhD}^{1}$, Jennifer J. Pells, \\ $\mathbf{P h D}^{1}$, Kim E. Dixon, $\mathbf{P h D}^{2}$, and James A. Blumenthal, $\mathbf{P h D}^{1}$ \\ 1 Department of Psychiatry and Behavioral Sciences, Duke University Medical Center, Durham, NC, United \\ States
}

2East Carolina University, Greenville, NC, United States

\begin{abstract}
This study examined whether self-efficacy mediated the relationship between pain catastrophizing and pain and disability. Participants were 192 individuals diagnosed with osteoarthritis (OA) of the knees who were overweight or obese. Multiple mediator analyses were conducted to simultaneously test self-efficacy for pain control, physical function, and emotional symptoms as mediators while controlling for demographic and medical status variables. Higher pain catastrophizing was associated with lower self-efficacy in all three domains $(p s<.05)$. Self-efficacy for pain control fully mediated the relationship between pain catastrophizing and pain ( $\beta=.08$, Sobel test $Z=1.97, p<.05)$. The relationship between pain catastrophizing and physical disability was fully mediated by self-efficacy for physical function $(\beta=.06$, Sobel test $\mathrm{Z}=1.95, p=.05$ ). Self-efficacy for emotional symptoms partially mediated the relationship between pain catastrophizing and psychological disability $(\beta=$. 12 , Sobel test $\mathrm{Z}=2.92, p<.05$ ). These results indicate that higher pain catastrophizing contributed to greater pain and disability via lower domain-specific self-efficacy. Efforts to reduce pain and improve functioning in OA patients should consider addressing pain catastrophizing and domain specific selfefficacy. Pain catastrophizing may be addressed through cognitive therapy techniques and selfefficacy may be enhanced through practice of relevant skills and personal accomplishments.
\end{abstract}

Perspective-This paper found that higher pain catastrophizing contributed to great pain and disability via domain specific self-efficacy. These results suggest that treatment efforts to reduce pain and improve functioning in OA patients who are overweight or obese should consider addressing both pain catastrophizing and self-efficacy.

\section{Keywords}

Catastrophizing; Self-efficacy; Pain; Disability; Osteoarthritis; Obesity

There is growing recognition that traditional biomedical model variables such as disease severity cannot sufficiently explain levels of pain and adjustment in patients with chronic pain. 25,42,50 Pain catastrophizing has consistently emerged as one of the most important

Corresponding Author: Rebecca A. Shelby. Duke University Medical Center, Box 90399, Durham, NC 27708, United States, Telephone: 919-416-3410; Fax: 919-416-3458; email: shelb003@mc.duke.edu.

Publisher's Disclaimer: This is a PDF file of an unedited manuscript that has been accepted for publication. As a service to our customers we are providing this early version of the manuscript. The manuscript will undergo copyediting, typesetting, and review of the resulting proof before it is published in its final citable form. Please note that during the production process errors may be discovered which could affect the content, and all legal disclaimers that apply to the journal pertain. 
psychological predictors of pain and disability. $13,20,21,22,41,42$ Pain catastrophizing is defined as the tendency to focus on and magnify pain sensations, and to feel helpless in the face of pain. ${ }^{42}$ Prospective studies indicate that pain catastrophizing is associated with increased pain, psychological disability, and activity intolerance. ${ }^{12,17,32,40,43}$ In recent intervention studies, reductions in pain catastrophizing have been linked with improvements in pain, physical functioning, and psychological adjustment. ${ }^{31,46,51}$ These findings underscore the importance of understanding how pain catastrophizing exerts its influence on patient outcomes.

Self-efficacy has also been recognized as an important variable in understanding how individuals adjust to chronic pain. ${ }^{10,26,27,52}$ Self-efficacy refers to the belief that one has the ability to successfully perform a specific behavior to achieve a particular outcome. ${ }^{3}$ Higher self-efficacy is associated with less pain and disability in chronic pain patients $10,11,36$ and strategies to enhance self-efficacy have been shown to reduce disability in arthritis patients. 28 We recently examined the contribution of arthritis self-efficacy to pain and disability in a sample of overweight and obese [body mass index (BMI) 25 to 42] patients with osteoarthritis (OA) of the knees. ${ }^{33}$ Analyses revealed that the contribution of self-efficacy was domainspecific; negative relationships were found between self-efficacy for pain control and pain, between self-efficacy for physical function and physical disability, and between self-efficacy for managing emotional symptoms and psychological disability.

Using data from this sample, ${ }^{33}$ the current study builds on our previous findings to examine the relationships between pain catastrophizing, arthritis self-efficacy, pain, and disability. Pain catastrophizing and self-efficacy may be especially relevant for understanding the processes that lead to disability in patients with OA of the knees who are overweight or obese. These individuals are likely to experience increased pain with movement. ${ }^{14}$ To avoid pain, patients may reduce physical activity, which could lead to further weight gain, greater disability, and increased pain. ${ }^{9}$ Understanding the role of pain catastrophizing and self-efficacy in initiating and maintaining this cycle is important for treatment efforts designed to reduce pain and improve functioning in this population.

The present study evaluated whether domain-specific arthritis self-efficacy mediated the relationship between pain catastrophizing and patient outcomes (pain and disability). We hypothesized that higher pain catastrophizing would be associated with lower self-efficacy in all domains, and domain specific self-efficacy would mediate the impact of pain catastrophizing on corresponding outcomes (e.g., self-efficacy for physical function would mediate the relationship between pain catastrophizing and physical disability).

\section{Materials and Methods}

\section{Participants}

Participants in this study were recruited through the Rheumatology, Orthopaedic Surgery, and Pain Management clinics at Duke University Medical Center (DUMC), through flyers posted throughout the community, and from advertisements in local newspapers. Most (85\%) participants were recruited through community and local advertisements, and $15 \%$ were recruited from DUMC clinics via physician referral. There were no statistically significant ( $p$ values >.25) differences between participants recruited from the community versus clinics on demographic, medical, or psychological variables. All study procedures and materials were approved by and in compliance with the Duke University Medical Center institutional review board. All participants in this study provided informed consent and were volunteers for a randomized trial of weight management and coping skills training known as the OA Life Study (\#NCT00305890). Data presented in this paper were collected in a subset of participants at the time of their baseline evaluation prior to randomization. 
Participants were 192 individuals diagnosed with OA of the knees who reported knee pain persisting for at least 6 months, and were overweight or obese (BMI between 25 and 42). All participants met the American College of Rheumatology criteria for OA, had radiographic evidence of OA affecting one or both knees, and OA of the knee(s) was the medical condition that contributed most to limitations in their daily function. Patients were excluded if they had a significant medical condition that increased their risk of a significant adverse health event during physical activity (e.g., myocardial infarction in the previous six months, an abnormal cardiac response to exercise such as exercise-induced BT or abnormal blood pressure response). Individuals with other arthritic disorders (e.g., rheumatoid arthritis) were also excluded. Participants were an average of $57(\mathrm{SD}=10)$ years of age, $79 \%$ of the sample was female, and education was as follows: $12 \%$ high school, $29 \%$ some college, $32 \%$ college graduate, and $27 \%$ professional/graduate school. The sample was 35\% African American, 63\% White, $1 \%$ Hispanic, and 1\% Asian/Pacific Islander. Participants had an average of 5 (SD=4) comorbid medical disorders, and average BMI was 34.28 ( $\mathrm{SD}=4.26$, range 25 to 42 ). Thirtyeight percent of participants had evidence of OA affecting one knee, and $62 \%$ had OA of both knees. On average, participants with OA of both knees were older than those with OA affecting one knee (Mean age $=59$ years vs. 55 years, respectively; $t=2.46, p=.02$ )

\section{Procedure and Measures}

Participants received bilateral knee x-rays, a medical evaluation, and completed a series of questionnaires to assess pain catastrophizing, arthritis-related self-efficacy, pain, physical disability, and psychological disability. Participants also provided demographic and medical information.

Osteoarthritis Diagnosis-The diagnosis of knee OA was based on the American College of Rheumatology clinical criteria for the classification of knee OA. ${ }^{1}$ These criteria have shown high sensitivity and specificity (> 90\%) for OA diagnosis. ${ }^{1}$ Radiographic assessment of both knees was used to confirm OA diagnosis. Study rheumatologists graded individual radiographic features of OA using a photographic standard atlas ${ }^{2}$ that included joint space narrowing and osteophytes and determined a score, based on Kellgren-Lawrence criteria. ${ }^{23}$ The average Kellgren-Lawrence score was $2.42(\mathrm{SD}=1.17)$ for the right knee and 2.43 $(\mathrm{SD}=1.19)$ for the left knee. Kellgren-Lawrence scores for each knee were summed resulting in a total score (range 1 to 8), with higher scores indicating greater disease severity.

Comorbid Medical Conditions-A list of 43 co-morbid medical conditions from the Older American Resources and Services (OARS) Physical Health Subscale ${ }^{15,16}$ was used to assess whether participants had co-morbid medical conditions. A total number of comorbid medical disorders was obtained for each patient.

Pain Catastrophizing - The tendency to use catastrophizing was assessed using the Catastrophizing Scale from the Coping Strategies Questionnaire (CSQ). ${ }^{37}$ This scale contains six items (e.g., "It is terrible and I feel it is never going to get any better," "It is awful and I feel it overwhelms me."). Patients rate the frequency that they engage in catastrophizing when experiencing moderate pain using a six-point scale $(0=$ never and $6=$ always $)$. For the current study, this scale had good internal reliability (Cronbach's alpha $=.81$ ).

Arthritis-related self-efficacy-The Arthritis Self-Efficacy Scale (ASES) ${ }^{26}$ was used to assess patients' perceived abilities to perform behaviors that would control arthritis pain and minimize disability. This measure is comprised of three subscales: pain control, other (emotional) arthritis symptoms, physical function. Patients are asked to indicate their responses on a $10-100(10=$ very uncertain; $100=$ very certain $)$ Likert-type scale. Subscale scores are obtained by averaging the responses to each item within a subscale, and subscale scores range 
from 10 to 100 . The ASES has demonstrated reliability and validity in past research. ${ }^{26,38}$ Internal consistency (Cronbach's alpha) in the current sample was .87 to .92 .

Pain, physical disability, and psychological disability-The Arthritis Impact Measurement Scales (AIMS) ${ }^{29}$ is a widely-used 45 -item self-report questionnaire designed to measure health status in arthritis patients. The AIMS provides three component summary scales: Pain, Physical Disability, and Psychological Disability. Summary scales range from 0 to 10 with higher scores indicating greater pain or disability. Reliability and validity of the three scales have been demonstrated across a number of arthritis populations, including osteoarthritis. ${ }^{19,30}$ In this sample, Cronbach's alpha was .76 for Pain, .80 for Physical Disability, and .92 for Psychological Disability.

\section{Results}

\section{Descriptive Statistics and Correlational Analyses}

Means, standard deviations, and correlations of study variables are displayed in Table 1. All correlations were in the expected directions and were moderate in magnitude. We computed correlations (Pearson or point-biserial) between study variables and socio-demographic/ medical variables to identify control variables for mediation analyses. Analyses revealed several statistically significant $(p<.05)$ relationships that were low in magnitude. Younger age $(r=-.24)$ and less education $(r=-.29)$ were associated with higher pain. Lower education $(r=$ $-.16)$, being female $(r=-.21)$, and having more comorbid medical disorders $(r=-.47)$ were associated with greater physical disability. Younger age $(r=-.24)$, less education $(r=-.16)$, being female $(r=-.21)$, and having more comorbid medical disorders were correlated with greater psychological disability. Higher scores on the three arthritis self-efficacy subscales were correlated with older age ( $r=.15$ to .22 ), more education ( $r=.19$ to .26 ), being male ( $r=$. 16 to .29), and having fewer comorbid medical disorders ( $r=-.20$ to -.23$)$. Pain catastrophizing was associated with younger age $(\mathrm{r}=-.31)$, less education $(\mathrm{r}=-.18)$, being female $(\mathrm{r}=-.20)$, and having more comorbid medical disorders $(r=.26)$. Thus, age, education, gender, and comorbid medical disorders were included in mediation analyses as control variables.

\section{Mediation Analyses}

Analyses were conducted to test whether arthritis self-efficacy subscales mediated the relationship between pain catastrophizing and pain or disability. Because three self-efficacy subscales were being tested as mediators, multiple mediator analyses were conducted using a macro 34,35 for SPSS that simultaneously tests multiple mediators, covariates, all possible pairwise comparisons between indirect effects, and produces bias-corrected confidence intervals for indirect effects. Figure 1 displays the multiple mediator model. A mediator (e.g., self-efficacy) carries the influence of the independent variable (e.g., pain catastrophizing) to the dependent variable (e.g., disability). According to Baron and Kenny, ${ }^{5}$ a variable can be considered a mediator if 1 ) the independent variable is related to the dependent variable (path $c$ in Figure 1),2) the independent variable is related to the mediator (paths $a_{1}, a_{2}$, and $a_{3}$ in Figure 1), 3) the mediator is related to the dependent variable after controlling for the independent variable (paths $b_{1}, b_{2}$, and $b_{3}$ in Figure 1), and 4) the relationship between the independent variable and the dependent variable is significantly reduced when the mediator is included (path $\mathrm{c}^{\prime}$ in Figure 1). The statistical significance of each regression coefficient was evaluated using the $\mathrm{t}$-test. The Sobel test ${ }^{39}$ was used to test the significance of indirect effects. Because assumptions of the Sobel test are often violated, ${ }^{7}$ we also examined the significance of indirect effects using a bootstrap approach (with 1000 resamples) to obtain bias-corrected $95 \%$ confidence intervals for the indirect effects. 34,35 This nonparametric approach reduces the likelihood of power problems caused by nonnormality of the indirect effect. ${ }^{34}$ Separate analyses were conducted for pain, physical disability, and psychological disability. Each 
analysis included gender, age, education, BMI, comorbid medical disorders, and OA severity (Kellgren-Lawrence total score) as control variables. Pain was included as a control variable in the analyses for disability.

\section{Pain}

Table 2 displays the standardized regression coefficients and tests of indirect effects for the multiple mediator analysis. The mediator model accounted for a significant amount of the variance in pain [total $\left.\mathrm{R}^{2}=33 \%, F(10,181)=9.02, p<.05\right]$. Higher pain catastrophizing was associated with lower self-efficacy for pain control $(\beta=-.40, p<.05)$, physical function $(\beta=-$. $22, p<.05)$, and other symptoms ( $\beta=-.42, p<.05)$. Greater self-efficacy for pain control was associated with lower pain $(\beta=-.20, p<.05)$, but self-efficacy for physical function and other symptoms were not related to pain ( $p$ values >.10). Consistent with full mediation, the total effect (path c) of pain catastrophizing on pain was significant, but the direct effect (path c') was substantially reduced and not significant (direct effect $\beta=.13, p=.09$ vs. total effect $\beta=.29$, $p<.001$ ). Evaluation of the indirect effect showed that self-efficacy for pain control mediated the relationship between pain catastrophizing and pain $(=.08,95 \% \mathrm{CI}=.004$ to.17, Sobel test $\mathrm{Z}=1.97, p<.05$ ). These results indicate that higher pain catastrophizing contributes to greater pain via lower self-efficacy for pain control.

\section{Physical disability}

The mediator model accounted for a significant amount of the variance in physical disability [total $\left.\mathrm{R}^{2}=48 \%, F(11,180)=14.91, p<.05\right]$. Again, higher pain catastrophizing was associated with lower self-efficacy for pain control, physical function, and other symptoms (see Table 2; $p$ values < .05). Consistent with our previous findings, 33 the contribution of self-efficacy was domain specific with only self-efficacy for physical function showing a negative association with physical disability $(\beta=-.36, p<.05)$. The relationship between pain catastrophizing and physical disability was fully mediated by self-efficacy for physical function, as the total effect (path c) of pain catastrophizing on physical disability was significant, but the direct effect (path $c^{\prime}$ ) was substantially reduced and not significant (direct effect $\beta=.13, p=.06$ vs. total effect $\beta=$. $17, p=.02$ ). Evaluation of the indirect effect confirmed that self-efficacy for physical function mediated the relationship between pain catastrophizing and physical disability $(\beta=.06,95 \% \mathrm{CI}$ $=.001$ to. 14 , Sobel test $Z=1.95, p=.05$ ). These results suggest that higher pain catastrophizing leads to greater physical disability through lowered self-efficacy for physical function.

\section{Psychological disability}

The mediator model accounted for a significant amount of the variance in psychological disability [total $\left.\mathrm{R}^{2}=45 \%, F(11,180)=13.32, p<.05\right]$. Table 2 displays the results of the multiple mediator analysis. Again, higher pain catastrophizing was associated with lower self-efficacy in all domains ( $p$ values <.05). Greater self-efficacy for other symptoms was associated with less psychological disability ( $\beta=-.35, p<.05)$, but self-efficacy for pain control and physical function were not associated with psychological disability ( $p$ values $>.28)$. Consistent with partial mediation, the direct effect (path c') of pain catastrophizing on psychological disability was lower than the total effect (path c), but remained significant (direct effect $\beta=.30, p<.001$ vs. total effect $=.41, p<.001$ ). Examination of the indirect effect confirmed that self-efficacy for other symptoms partially mediated the relationship between pain catastrophizing and psychological disability $((\beta=.12,95 \% \mathrm{CI}=.05$ to.22, Sobel test $\mathrm{Z}=2.92, p<.05)$. These results suggest that pain catastrophizing leads to greater psychological disability directly and through lower self-efficacy for managing emotional symptoms. 


\section{Discussion}

The current study builds on our previous findings in a sample of patients with OA of the knees.

33 Using data from this sample, we found that domain-specific self-efficacy mediated the relationship between pain catastrophizing and adjustment. Studies in patients with chronic pain consistently identify self-efficacy and pain catastrophizing as important predictors of adjustment. $10,11,20,21,22,36,41,42$ Our analyses found that both variables are important for understanding the processes that lead to increased disability. These findings suggest that the impact of pain catastrophizing occurs through patients' self-efficacy in specific domains. For example, pain catastrophizing leads to greater physical disability through lowered self-efficacy for physical function and leads to greater psychological disability through lowered self-efficacy for managing psychological symptoms.

These findings suggest that both pain catastrophizing and domain specific self-efficacy warrant attention in future treatment efforts. Pain catastrophizing may be best addressed through cognitive therapy techniques, such as cognitive restructuring, that aim to reduce distorted, irrational, or overly negative thinking. ${ }^{6}$ Systematic training in recognizing, evaluating, and modifying overly negative cognitions may be particularly helpful for reducing pain catastrophizing. Thorn and colleagues 44 recently tested the efficacy of a cognitive-behavioral treatment targeting pain catastrophizing in patients with chronic headaches. This cognitive restructuring intervention reduced catastrophizing and anxiety and increased self-efficacy. This intervention protocol could be adapted for patients with OA, and additional strategies could be incorporated to further enhance domain specific self-efficacy. A number of strategies can be used to enhance self-efficacy including development and practice of relevant skills, observation of others, and personal accomplishments. ${ }^{3,4}$ Interventions that involve successful accomplishment of particular tasks could be particularly powerful for increasing self-efficacy because it provides personal experiences of mastery. ${ }^{3}$ Vlaeyan and colleagues ${ }^{48,49}$ have developed in vivo graded exposure techniques that enable patients with pain to experience and habituate to activities they might normally avoid. Graded exposure might be a useful method for enhancing self-efficacy because it requires patients to engage in and accomplish a feared or painful activity. 52

Our findings also have implications for the temporal sequence of treatment for overweight and obese OA patients. Healthcare providers may recommend weight loss as an initial strategy for reducing OA pain and disability. Adhering to recommendations for weight loss may pose a significant challenge for patients who catastrophize and/or have low self-efficacy. These individuals may be less likely to adhere to exercise recommendations because they lack confidence in their ability to engage in physical activity and they fear that such activity will exacerbate their pain (a characteristic of catastrophizing) ${ }^{45}$ Further, adhering to dietary recommendations for weight loss may be more difficult for patients who catastrophize. Our data suggest that higher catastrophizing is associated with lower self-efficacy in all domains, and lower self-efficacy for resisting eating is related to poor eating habits. ${ }^{33}$ In addition, catastrophizing is associated with greater psychological disability. Past research has shown that patients with higher levels of psychological disability, such as depression, have poorer adherence to healthy dietary recommendations. ${ }^{8}$ To increase the chance of success when weight loss efforts are initiated, treatment efforts could include strategies for reducing pain catastrophizing and increasing self-efficacy either prior to targeting weight loss or as part of the weight loss program.

This study had several limitations. First, this study used a correlational design, which prevents us from making causal attributions about the relationships between pain catastrophizing, selfefficacy, and disability. Self-efficacy only partially mediated the relationship between pain catastrophizing and psychological disability; the correlational study design makes it impossible 
to determine if catastrophizing influenced psychological disability through self-efficacy or vice versa. Future research is needed to more closely evaluate cause-effect relationships between pain catastrophizing, domain specific self-efficacy, and disability. For example, studies could be conducted to examine whether interventions that alter pain catastrophizing lead to significant changes in self-efficacy. Second, the number of statistical tests conducted may have inflated Type I error. While multiple mediator analyses were conducted, the family wise error resulting from correlational analyses and separate models for each outcome should be considered when interpreting the results. Third, our findings may be less generalizable because data were obtained from patients who agreed to participate in a treatment study that targets pain reduction and weight control. Individuals who voluntarily seek participation in clinical trials may differ from patients in the general population. Finally, additional studies are needed to determine if these findings generalize to patients with chronic pain conditions other than OA of the knees.

In summary, this study found that pain catastrophizing led to greater pain and disability through lowered domain specific self-efficacy. It is important to note that these findings were obtained after controlling for demographic (e.g., age, sex, education) and medical status variables (e.g., disease severity, comorbid medical disorders, BMI) traditionally considered important for understanding pain and disability in this population. ${ }^{18,24}$ Additional studies are needed to examine how self-efficacy beliefs and pain cognitions, such as pain catastrophizing, contribute to adjustment. The fear-avoidance model ${ }^{49}$ may be relevant for understanding the processes that lead to increased disability in overweight or obese patients with OA of the knees. This model suggests that catastrophizing about pain initiates a vicious cycle that leads to painrelated fear, avoidance of activities, and ultimately greater disability and pain. A recent study 52 of the fear-avoidance model found that pain-related fear impacted patient outcomes through lowered self-efficacy, suggesting that the fear-avoidance model could be improved by including self-efficacy beliefs. Future studies could test a fear-avoidance model that includes self-efficacy as a framework for understanding and intervening in the processes that contribute to increased pain and disability in overweight and obese patients with OA of the knees.

\section{Acknowledgements}

This study was supported by NIH Grant \#1P01AR50245-03.

\section{References}

1. Altman R, Asch E, Bloch D, Bole G, Borenstein D, Brandt K, Christy W, Cooke TD, Greenwald R, Hochberg M, Howell D, Kaplan D, Koopman W, Longley S, Mankin H, McShane DJ, Medsger T, Meenan R, Mikkelsen W, Moskowitz R, Murphy W, Rothschild B, Segal M, Sokoloff L, Wolfe E. Development of criteria for the classification and reporting of osteoarthritis. Classification of osteoarthritis of the knee. Diagnostic and Therapeutic Criteria Committee of the American Rheumatism Association. Arthritis Rheum 1986;29:1039-1049. [PubMed: 3741515]

2. Altman RD, Hochberg M, Murphy WA Jr, Wolfe F, Lequesne M. Atlas of individual radiographic features in osteoarthritis. Osteoarthritis Cartilage 1995;3:3-70. [PubMed: 8581752]

3. Bandura A. Self-efficacy: Toward a unifying theory of behavioral change. Psychol Rev 1977;84:191215. [PubMed: 847061]

4. Bandura, A. Social foundations of thought and action: a social cognitive theory. Englewood Cliffs, NJ: Prentice-Hall Inc; 1986.

5. Baron RM, Kenny DA. The moderator-mediator variable distinction in social psychological research: Conceptual, strategic, and statistical considerations. J Pers Soc Psychol 1986;51:1173-1182. [PubMed: 3806354]

6. Beck, AT. Depression: Causes and Treatment. Philadelphia, PA,: University Pennsylvania Press; 1972.

7. Bollen KA, Stine R. Direct and indirect effects: classical and bootstrap estimates of variability. Sociological Methodology 1990;20:115-140. 
8. Bonnet F, Irving K, Terra JL, Nony P, Berthezene F, Moulin P. Anxiety and depression are associated with unhealthy lifestyle in patients at risk of cardiovascular disease. Atherosclerosis 2005;178:339_ 344. [PubMed: 15694943]

9. Bunning RD, Materson RS. A rational program of exercise for patients with osteoarthritis. Semin Arthritis Rheum 1991;21:33-43. [PubMed: 1796304]

10. Denison E, Asenlof P, Lindberg P. Self-efficacy, fear avoidance, and pain intensity as predictors of disability in subacute and chronic musculoskeletal pain patients in primary health care. Pain 2004;111:245-252. [PubMed: 15363867]

11. Dohnke B, Knauper B, Muller-Fahrnow W. Perceived self-efficacy gained from, and health effects of, a rehabilitation program after hip joint replacement. Arthritis Rheum 2005;53:585-592. [PubMed: 16082655]

12. Edwards RR, Fillingim RB, Maixner W, Sigurdsson A, Haythornthwaite J. Catastrophizing predicts changes in thermal pain responses after resolution of acute dental pain. J Pain 2004;5:164-170. [PubMed: 15106129]

13. Esteve R, Ramirez-Maestre C, Lopez-Marinez AE. Adjustment to chronic pain: the role of pain acceptance, coping strategies, and pain-related cognitions. Ann Behav Med 2007;33:179-188. [PubMed: 17447870]

14. Felson, DT. Epidemiology of osteoarthritis. In: Brandt, KD.; Lohmander, LS.; Doherty, M., editors. Osteoarthritis. Oxford: Oxford University Press; 1998. p. 13-22.

15. Fillenbaum, GG. Multidimensional functional assessment of older adults: The Duke Older Americans Resources and Services Procedures. Hilldale, NJ: Lawrence Erlbaum Associates; 1988.

16. George LK, Fillenbaum GG. OARS methodology. A decade of experience in geriatric assessment. J Am Geriatr Soc 1985;33:607-615. [PubMed: 4031339]

17. Haythornthwaite JA, Clark MR, Pappagallo M, Raja SN. Pain coping strategies play a role in the persistence of pain in post-herpetic neuralgia. Pain 2003;106:453-460. [PubMed: 14659529]

18. Jordan JM, Luta G, Renner JB, Linder GF, Dragomr A, Hochberg MC, Fryer JG. Self-reported functional status in osteoarthritis of the knee in a rural southern community: The role of sociodemographic factors, obesity, and knee pain. Arth Care and Res 1996;9:273-278. [PubMed: 8997916]

19. Kazis LE, Meenan RF, Anderson J. Pain in the rheumatic diseases: Investigations of a key health status component. Arthritis Rheum 1983;26:1017-1022. [PubMed: 6603848]

20. Keefe FJ, Brown GK, Wallston KA, Caldwell DS. Coping with rheumatoid arthritis pain: catastrophizing as a maladaptive strategy. Pain 1989;37:51-56. [PubMed: 2726278]

21. Keefe FJ, Caldwell DS, Queen KT, Gil KM, Martinez S, Crisson JE, Ogden W, Nunley J. Osteoarthritis knee pain: a behavioral analysis. Pain 1987;28:308-321.

22. Keefe FJ, Lefebvre JC, Egert JR, Affleck G, Sullivan MJ, Caldwell DS. The relationship of gender to pain, pain behavior, and disability in osteoarthritis patients: the role of catastrophizing. Pain 2000;87:325-334. [PubMed: 10963912]

23. Kellgren JH, Lawrence JS. Radiological assessment of osteo-arthritis. Ann Rheum Dis 1957;16:494502. [PubMed: 13498604]

24. Larsson UE, Mattsson E. Functional limitations linked to high body mass index, age and current pain in obese women. Int J Obes Relat Metab Disord 2001;25:893-899. [PubMed: 11439305]

25. Leeuw M, Goossens MEJB, Linton SJ, Crombez G, Boersma K, Vlaeyen JWS. The fear-avoidance model of musculoskeletal pain: current state of scientific evidence. J Behav Med 2007;30:77-94. [PubMed: 17180640]

26. Lorig K, Chastain RL, Ung E, Shoor S, Holman HR. Development and evaluation of a scale to measure perceived self-efficacy in people with arthritis. Arthritis Rheum 1989;32:37. [PubMed: 2912463]

27. Manne SL, Zautra AJ. Coping with arthritis: current status and critique. Arthritis Rheum 1992;35:1273-1280. [PubMed: 1445442]

28. Marks R. Efficacy theory and its utility in arthritis rehabilitation: review and recommendations. Disabil Rehabil 2001;23:271-280. [PubMed: 11354579]

29. Meenan RF, Gertman PM, Mason JH. Measuring health status in arthritis: The Arthritis Impact Measurement Scales. Arthritis Rheum 1980;23:146-152. [PubMed: 7362665] 
30. Meenan RF, Gertman PM, Mason JH, Dunaif R. The Arthritis Impact Measurement Scales: Further investigation of a health status measure. Arthritis Rheum 1982;25:1048-1053. [PubMed: 7126289]

31. Moss-Morris R, Humphrey K, Johnson MH, Petrie KJ. Patients' perceptions of their pain condition across a multidisciplinary pain management program: do they change and if so does it matter? Clin J Pain 2007;23:558-564. [PubMed: 17710004]

32. Pavlin DJ, Sullivan MJ, Freund PR, Roesen K. Catastrophizing: a risk factor for postsurgical pain. Clin J Pain 2005;21:83-90. [PubMed: 15599135]

33. Pells JJ, Shelby RA, Keefe FJ, Dixon KE, Blumenthal JA, LaCaille L, Tucker JM, Schmitt D, Caldwell DS, Kraus VB. Arthritis self-efficacy and self-efficacy for resisting eating: relationships to pain disability, and eating behavior in overweight and obese individuals with osteoarthritis knee pain. Pain 2008;136:340-347. [PubMed: 17764844]

34. Preacher KJ, Hayes AF. SPSS and SAS procedures for estimating indirect effects in simple mediation models. Behav Res Methods 2004;36:717-731.

35. Preacher, KJ.; Hayes, AF. Asymptotic and resampling strategies for assessing and comparing indirect effects in multiple mediator models. Available at http://www.comm.ohio-state.edu/ahayes/indirect2.pdf

36. Reid MC, Williams CS, Gill TM. The relationship between psychological factors and disabling musculoskeletal pain in community-dwelling older persons. J Am Geriatr Soc 2003;51:1092-1098. [PubMed: 12890071]

37. Rosentiel AK, Keefe FJ. The use of coping strategies in chronic low back pain patients: relationship to patient characteristics and current adjustment. Pain 1983;17:33-44. [PubMed: 6226916]

38. Schiaffino KM, Revenson TA, Gibofsky A. Assessing the impact of self-efficacy beliefs on adaptation to rheumatoid arthritis. Patient Educ Couns 1991;20:177-187.

39. Sobel ME. Asymptotic intervals for indirect effects in structural equation models. Sociological Methodology 1982;13:290-312.

40. Sullivan MJ, Rodgers WM, Wilson PM, Bell GJ, Murray TC, Fraser SN. An experimental investigation of the relation between catastrophizing and activity intolerance. Pain 2002;100:47-53. [PubMed: 12435458]

41. Sullivan MJ, Stanish W, Waite H, Sullivan M, Tripp DA. Catastrophizing, pain, and disability in patients with soft-tissue injuries. Pain 1998;77:253-260. [PubMed: 9808350]

42. Sullivan MJL, Thorn B, Haythornwaite JA, Keefe F, Martin M, Bradley LA, Lefebvre JC. Theoretical perspectives on the relation between catastrophizing and pain. Clin J Pain 2001;17:52-64. [PubMed: 11289089]

43. Sullivan MJL, Thorn B, Rodgers W, Ward LC. Path model of psychological antecedents to pain experience: experimental and clinical findings. Clin J Pain 2004;20:164-173. [PubMed: 15100592]

44. Thorn BE, Pence LB, Ward LC, Kilgo G, Clements KL, Cross TH, Davis AM, Tsui PW. A randomized clinical trial of targeted cognitive behavioral treatment to reduce catastrophizing in chronic headache sufferers. J Pain 2007;8:938-949. [PubMed: 17690017]

45. Turner JA, Aaron LA. Pain-related catastrophizing: what is it? Clin J Pain 2001;17:65-71. [PubMed: 11289090]

46. Turner JA, Holtzman S, Mancl L. Mediators, moderators, and predictors of therapeutic change in cognitive-behavioral therapy for chronic pain. Pain 2007;127:276-286. [PubMed: 17071000]

47. Vlaeyen JW, de Jong J, Geilen M, Heuts PH, van Breukelen G. Graded exposure in vivo in the treatment of pain-related fear: a replicated single-case experimental design in four patients with chronic low back pain. Behav Res Ther 2001;39:151-166. [PubMed: 11153970]

48. Vlaeyen JW, de Jong J, Geilen M, Heuts PH, van Breukelen G. The treatment of fear of movement/ (re)injury in chronic low back pain: further evidence on the effectiveness of exposure in vivo. Clin J Pain 2002;18:251-261. [PubMed: 12131067]

49. Vlaeyen JWS, Kole-Snijders AMJ, Boeren RGB, van Eek H. Fear of movement/(re) injury in chronic low back pain and its relation to behavioral performance. Pain 1995;62:363-372. [PubMed: 8657437]

50. Vlaeyen JWS, Linton SJ. Fear-avoidance and its consequences in chronic musculoskeletal pain: a state of the art. Pain 2000;85:317-332. [PubMed: 10781906] 
51. Vowles KE, McCracken LM, Eccleston C. Processes of change in treatment for chronic pain: the contributions of pain, acceptance, and catastrophizing. Eur J Pain 2007;11:779-787. [PubMed: 17303452]

52. Woby SR, Urmston M, Watson PJ. Self-efficacy mediates the relation between pain-related fear and outcome in chronic low back pain patients. Eur J Pain 2007;11:711-718. [PubMed: 17218132] 

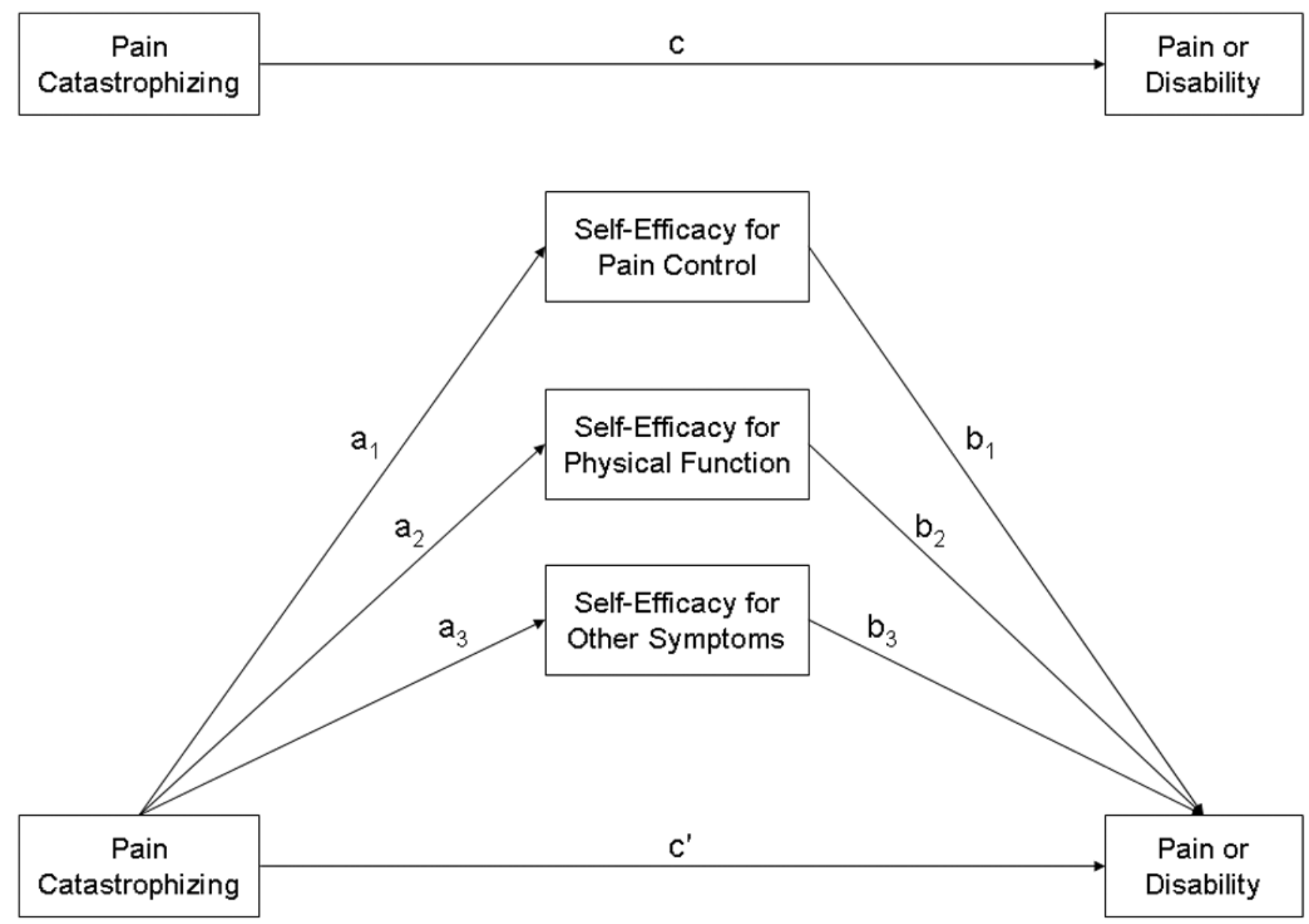

Figure 1.

Multiple mediator model testing whether self-efficacy mediates the relationship between catastrophizing and pain or disability.

Note: Analyses included gender, age, education, BMI, comorbid medical disorders, and OA severity (Kellgren-Lawrence total score) as control variables. Analyses for disability included pain as a control variable. To simplify presentation, control variables are not displayed. 


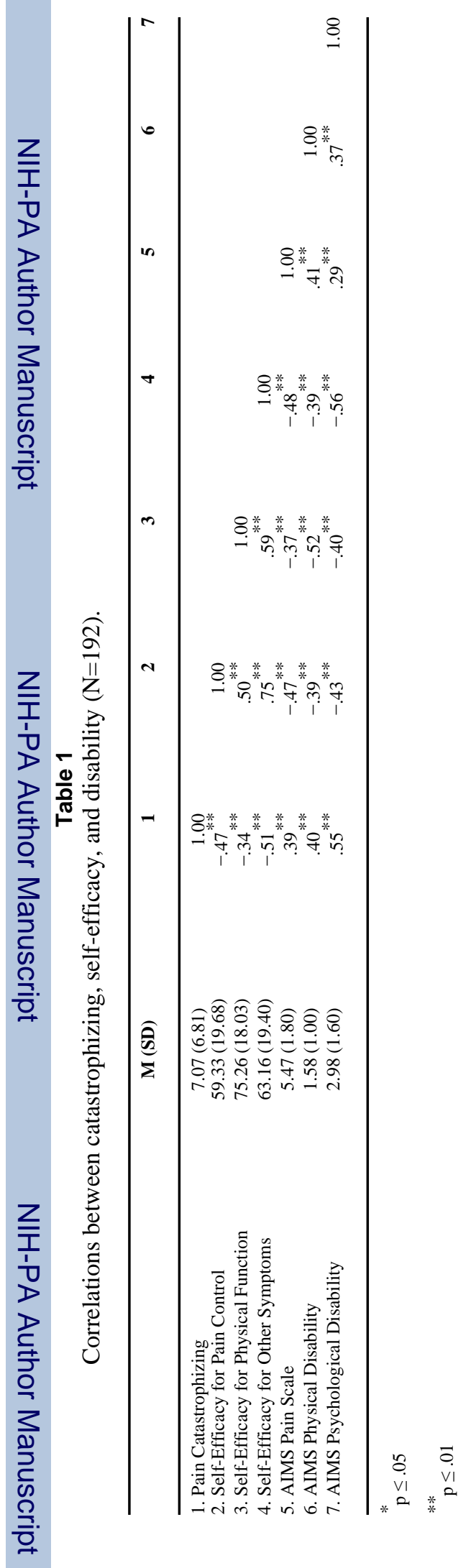


Shelby et al.

Page 13

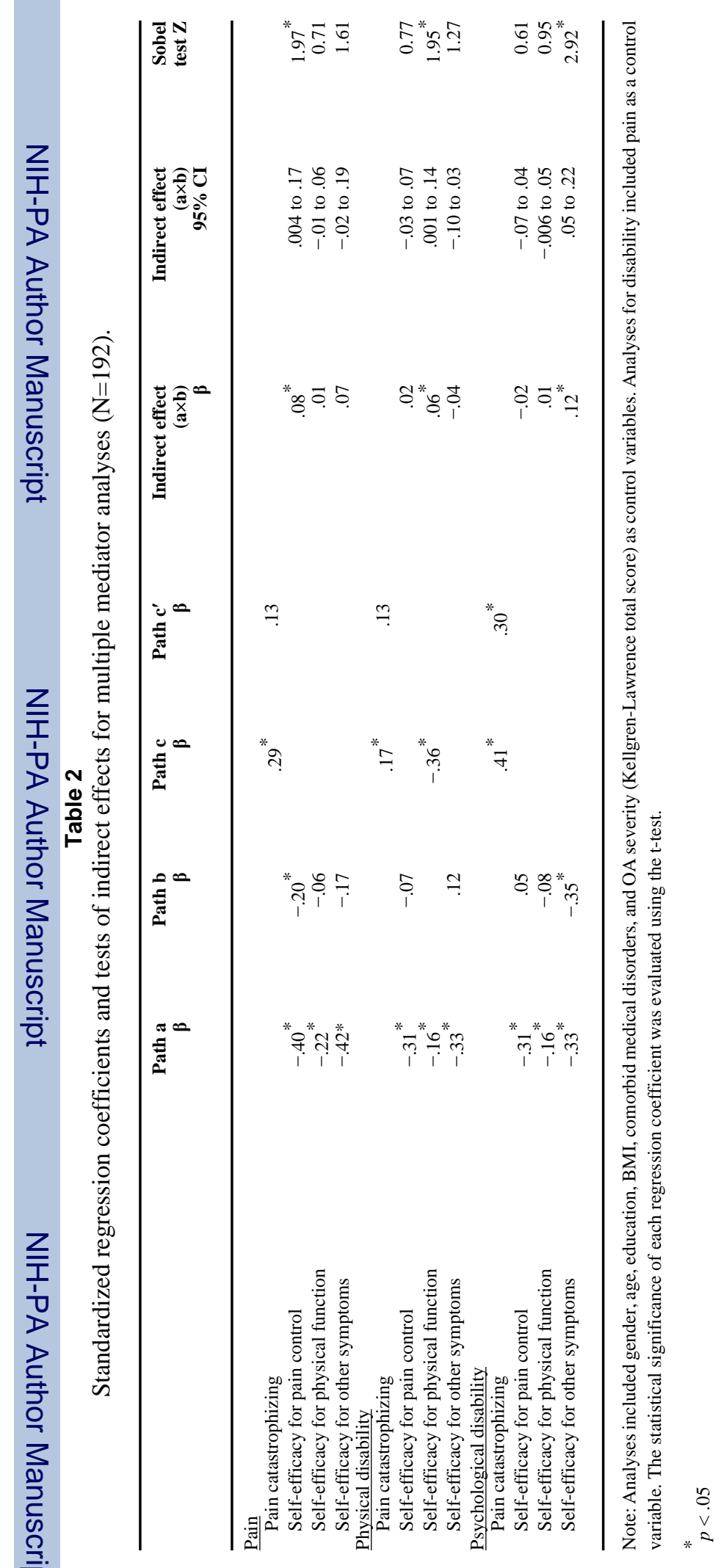

J Pain. Author manuscript; available in PMC 2009 October 1. 